\title{
Prefacio: Escrituración Femenina de lo Cotidiano
}

\author{
M. José Rodríguez Campillo* \\ Universitat Rovira i Virgili, Tarragona, Spain
}

(Henry Tilney): ¡No llevar un diario! ¿Cómo van a comprender entonces sus primas ausentes el curso de su vida en Bath? (...) Todo el mundo admite que el talento para escribir cartas agradables es una cualidad femenina. La naturaleza puede haber contribuido en algo, pero estoy seguro que, por fuerza, la práctica diaria

debe influir de una manera esencial

(Austen 1817 [1983]: 207)

En este volumen vamos a encontrarnos con algunas mujeres que escribieron sobre lo cotidiano, sobre lo que les sucedía o les preocupaba en algunos momentos concretos de su vida. Esta escritura femenina se presenta en forma de cartas; cartas manuscritas o, según suponen algunos estudiosos, dictadas a alguien.

Estas cartas presentan una pequeña muestra de las muchas mujeres que tuvieron que vivir confinadas en el silencio, sumisas al poder de los hombres, y que se revelan a través de sus escritos. Las cartas femeninas suelen ser simples,

\footnotetext{
* Author's address:

Departament de Filologies Romàniques

Universitat Rovira i Virgili

Av. Catalunya 35, 43002 Tarragona, Spain

E-mail josefa.rodriguez@urv.cat
} 
con la mera finalidad de trasmitirnos alguna noticia, de pedir o agradecer algo a alguien, o de felicitar o dar el pésame a sus allegados.

Las cartas que se analizan en este volumen son cartas que ofrecen un pequeño recorrido por algunas de las aportaciones femeninas a la literatura castellana en forma epistolar. Son cartas que responden, la mayoría de las veces, a la necesidad de relacionarse, de comunicarle al mundo lo que ellas sienten, piensan o, simplemente, observan. Y, por ello, nos acercan a su entorno, a su historia más inmediata, a nuestra propia historia. Estas cartas nos permiten adentrarnos en sus pensamientos más íntimos, en sus sentimientos e, incluso, en sus vivencias cotidianas; unas vivencias cotidianas que nos acercan a la sensibilidad y mentalidad de esas mujeres.

La mayoría de las mujeres ha respetado, durante siglos, el limitado marco (vital, ideológico o moral) que les había sido concedido por los hombres. Sin embargo, algunas de ellas, logran escapar a esas normas (no de una manera muy brusca) y logran comunicarnos qué piensan, qué sienten, e incluso, logran ofrecernos alguna queja velada de las injusticias que las mujeres de su época y, por supuesto ellas mismas, sufren: y todo ello es lo que hacen en las cartas que aparecen en este volumen.

Los artículos incluidos en este volumen han sido ordenados cronológicamente. En primer lugar, encontramos el trabajo dedicado a Teresa de Cartagena. En él, Víctor Pascual Durán y M. José Rodríguez Campillo nos hablan de "La voz silenciada en los textos medievales: Una carta de Teresa de Cartagena". En el artículo, se revisan aquellos aspectos contenidos en la carta titulada Admiraçion Operum Dey, de Teresa de Cartagena, que están relacionados con el universo femenino, los elementos que devienen esenciales para indagar en la obra escrita por una monja en un contexto medieval, patriarcal y eminentemente misógino. Esta obra se convierte en un auténtico alegato a favor del derecho de la mujer al acceso a la cultura y, más en concreto, a la escritura.

El segundo artículo, a cargo de la Dra. Coral Cuadrada y el Dr. Enric Olartecoechea y titulado "Cuerpos públicos. Cartas privadas", nos desvela la correspondencia entre dos aristócratas de los Siglos de Oro, Luisa de Carvajal y Magdalena de san Jerónimo. A partir del análisis de la correspondencia de estas dos aristócratas, los autores del artículo nos conectan tres espacios públicos ocupados por mujeres del momento: el prostíbulo, el teatro y la Casa Pía o cárcel para mujeres "de mal vivir" que quieren redimirse. Magdalena de san Jerónimo conecta esos tres espacios: ella da al público partes del cuerpo de las vírgenes (reliquias que había estado recogiendo por toda Europa) y, 
a cambio, el monarca decreta que una parte del impuesto sobre el teatro (ocupado ya por actrices también) vaya a parar a la casa de las Magdalenas. Ese dinero ayuda a las mujeres de allí, arrepentidas, cuyo "crimen" había sido el comercio y exhibición pública de sus cuerpos. Exhibición que también hacen, en alguna medida y según la mentalidad de la época, las actrices teatrales cada noche de espectáculo. La misma tensión entre lo público y lo privado se ve en los distintos escenarios públicos: procesión de reliquias por toda Europa hasta llegar a España para ser salvadas de la destrucción; procesión de prostitutas desde la casa pública donde trabajan hasta la de las Magdalenas, para salvarlas del pecado; y procesión de las actrices en el escenario, y de un escenario a otro. Y un subtexto que las une a todas ellas: el mito de la Magdalena. Las prostitutas pueden extender enfermedades y las reliquias de la Virgen mártir, curarlas. La mujer pública es un cuerpo abierto, en "marcada oposición al cerrado de la Virgen". Y las arrepentidas son la promesa de la pureza del alma, como María Magdalena. Al finalizar el artículo, los autores se permiten una conexión más: las reliquias del Imperio de la época en que estas aristócratas vivieron.

A continuación, damos un salto en el tiempo y nos situamos a finales del siglo XIX y principios del XX, una época que permitió, paulatinamente, el acceso de la mujer a la cultura. Este cambio se aprecia en los siguientes artículos.

El artículo de Ginés Puente Pérez, titulado "Correspondencia entre rejas. La defensa de la libertad por Teresa Mañé Miravent", analiza las relaciones epistolares de Teresa Mañé, una de las mujeres más importantes en la formación del pensamiento anarquista en la España de finales del XIX y primeras décadas del XX. Este análisis se enfrenta, sobre todo, con la problemática de la censura u ocultación de muchas de esas cartas, pues el control y reprensión, en aquella época, estaban a la orden del día. Pero, como dice el autor, "conseguir desvelar algunos de estos silencios (...), en este caso la lucha de Teresa Mañé con respecto a los presos obreros, se presenta como una labor necesaria". Y eso es lo que él mismo nos ofrece en su artículo.

El artículo "Indagando en los silencios del franquismo: carta de una mujer ingresada en un manicomio de Gipuzkoa", de Itxaso Martin Zapirain, "indaga" en la carta y notas recogidas en el informe clínico de una mujer, Carole, que estuvo ingresada en un manicomio durante la época franquista para, así, intentar componer la imagen de la sociedad de aquella época (1949-1950). Tras el análisis de su antibiografía y la construcción del contexto que rodea 
a esta mujer, se concluye que "Carole llegó a poner en tela de juicio el rol de mujer que planteaba el régimen franquista", un rol que en la España de los cincuenta era el de "una mujer sumisa, casera, católica y cuidadora". Así, todo comportamiento en una mujer que "se situara fuera de este modelo" era considerado, en algunos casos, como una enfermedad, enfermedad por la cual Carole estuvo durante casi un año en el psiquiátrico de Gipuzkoa.

En el último artículo incluido en este volumen, titulado "Las narraciones diferentes del parto: Las geormetrías relacionales", Serena Brigidi nos hace reflexionar, "re-pensar" la maternidad como categoría literaria, como un "elemento biográfico". Su objetivo es analizar el parto "como un proceso ontológico de transformación a partir de unas narrativas diferentes" como, por ejemplo, las que nos ofrecen Isabel Allende o Laura Esquivel. Porque el parto es "un testimonio, una memoria, una historia, una narración, un relato". Y, por ello, el parto "se narra", "se recuerda", "se baila", es "un inicio, un cuento biográfico, una memoria que teje las primeras relaciones humanas". Con todo ello, lo que pretende su autora, Serena Brigidi, es analizar algunos relatos distintos sobre el parto, elegidos por ella misma, pues defiende que la maternidad es "un discurso ontológico racional" que no debemos rechazar y sí conocer.

En definitiva, aunque "simplemente" sean cartas lo que se ha analizado en este volumen, hay que reconocerlas, a todas ellas, como piezas fundamentales para la historia de la literatura castellana, como una muestra de la pequeña aportación que la mujer hace a la misma con su "escrituración femenina de lo cotidiano".

\section{Bibliografía}

1. Austen, J. (1817). La abadía de Northanger. Madrid: Bruguera [1983]. 